\title{
Academic Entrepreneurial Intention and Its Determinants: Exploring the Moderating Role of Innovation Ecosystem
}

\author{
Massimiliano Vesci ${ }^{1}$, Antonio Botti ${ }^{1}$, Rosangela Feola ${ }^{1} \&$ Chiara Crudele ${ }^{1}$ \\ ${ }^{1}$ Department of Management \& Innovation Systems, University of Salerno, Italy \\ Correspondence: Antonio Botti, Department of Management \& Innovation Systems, University of Salerno, Italy. \\ E-mail: abotti@unisa.it
}

Received: May 12, 2020

Accepted: June 14, 2020

Online Published: July 2, 2020

doi:10.5539/ijbm.v15n8p39

URL: https://doi.org/10.5539/ijbm.v15n8p39

\begin{abstract}
The paper aims to study factors that affect entrepreneurial intention among academicians (Prodan \& Drnovsek 2010). We develop a framework in which the classical intention determinants derived from the Theory of Planned Behavior (TPB, Ajzen, 1991) interact with some elements of the environmental innovation ecosystem as identified in the Triple Helix Model (THM, Etzkovitz et al., 2007), namely financial/industrial, university and government supports. We contend that when individuals perceive high support from all these factors, the predictive power of entrepreneurial attitude, perceived behavioral control and social norms in shaping academic entrepreneurial intention generally increases. This study theoretically advances research on academic entrepreneurial intention, highlighting the interplay between individual cognitions and environmental cues and proposes some insights for practice and national policy makers.
\end{abstract}

Keywords: academic entrepreneurial intention, theory of planned behavior, innovation ecosystem, triple Helix model

\section{Introduction}

Academic Entrepreneurial Intention (AEI), that is the intention of an academic person to promote a new company based on the outcomes of scientific research (Clarysse, Heirman, \& Degroof, 2000), in the last years, has granted interest from an increasing number of entrepreneurship researchers (Prodan \& Drnovsek 2010; Goethner, Obschonka, Silbereisen, \& Cantner, 2012; Ozgul, \& Kunday 2015; Mosey, Noke, \& Binks, 2012).

As career choice processes are cognitive in nature, when individuals decide to enroll in an entrepreneurship career, they lay in a process in which thoughts, mentality, behavior and intentional elements are central (Krueger, Reilly \&, Carsrud, 2000). As such, following social cognition stream of literature, behavioral intentions (Wilson, Kickul, \& Marlino, 2007; Lanero, Vázquez, Gutiérrez \& García, 2015; Peterman \& Kennedy 2003) are considered strong predictors of consequent entrepreneurial behavior that lead to the aforementioned deliberate career choice. Starting from the intentionality characteristic of the entrepreneurial process (Krueger et al., 2000; Kolvereid, 2016), studies on AEI have generally adopted the TPB (Ajzen, 1991) to study elements that influence entrepreneurial intention in academic context (Goethner et al. 2012; Obschonka et al. 2012, 2015). The studies published in recent years identify different antecedents of AEI and generally focus on both perceptual and psychological factors at individual level (Prodan, \& Drnovsek 2010; Huyghe, \& Knockaert 2015; Goethner et al. 2012; Obschonka et al. 2012; 2015; Feola, Vesci, Botti, \& Parente, 2017). In the meantime, external context and exogenous factors have been considered and analyzed with specific reference to AEI (see for example: Moog, Werner, Houweling, \& Backes-Gellner, 2015; Foo, Knockaert, Chan, \& Erikson, 2016; Guerrero \& Urbano, 2014).

However, the review of the literature highlights that AEI research focuses on the separate analysis of psychological and contextual determinants, neglecting to deeply analyze the interacting effects among the endogenous (psychological) and exogenous (contextual) level from a cognitive perspective. In this specific context, many authors (Cooke \& Sheran, 2004; Carsrud \& Brännback, 2011; Moriano, Gorgievski, Laguna, Stephan, \& Zarafshani, 2012; Shook, Priem, \& McGee, 2003; Liñán, Urbano \& Guerrero, 2011) hint to study the moderating effects of contextual factors and environment in order to better explain the direct effects of psychological determinants. As stated by some studies (Kibler, 2013; Schlaegel \& Koenig, 2013) the inclusion of external moderators' factors could increase the explanatory power of intentional models. 
To fill this gap, the present study investigates the moderating effects of some relevant dimensions of external environment on the relationships between the cognitive dimension and AEI. To reach this goal, our research drawn from two theories, namely the TPB (Ajzen, 1991) and the Triple Helix Model (Etzkowitz, Dzisah, Ranga, \& Zhou, 2007), in order to select traditional antecedents (attitude, perceived behavioral control, subjective norm) of entrepreneurial intention and the most relevant dimensions of external context (Industry and Finance, University, Government).

We tested our hypotheses on a group of young researchers (PhD Students), that in Academic Entrepreneurship research has been considered a crucial area of investigation, representing the potential future generation of academics and a natural channel for the realization of technology transfer processes (Bienkowska, Klofsten, \& Rasmussen, 2016).

The present study leads to some implications, both theoretical and practical. Conceptualizing a model that investigates, adopting a behavioral approach, the effect of external factors in terms of changing the relationship between well-established traditional variables, we contribute to the academic entrepreneurship research field and more specifically to the literature on AEI. Further, the study has several implications in terms of strategies and actions aimed at stimulating the entrepreneurial intentions of academics.

The paper is structured as follows. In Section 2, we present the theoretical framework of the paper exploring the concept of AEI and describing the TPB approach and the THM. Section 3 illustrates the conceptual model and the development of hypotheses. Section 4 describes the research design and the empirical analysis. Section 5 highlights the results of the study, Sections 6 and 7 discuss the findings and the main implications of the study and Section 8 concludes suggesting the future research trajectories.

\section{Theoretical Framework}

\subsection{Academic Entrepreneurial Intention and Its Determinants: The Theory of Planned Behavior}

AEI represents the intention of a research-trained person to give birth to a new entrepreneurial firm starting from the results of his own research (Clarysse et al., 2000; Prodan, \& Drnovsek 2010; Feola et al. 2017). AEI concept has been developed in academic entrepreneurship research context that in the last years has been receiving an increasing attention by scholars (Siegel \& Wright, 2015) and policy makers. In this perspective, research on AEI focuses on the analysis of the factors that lead academic people to involve in entrepreneurial behavior (Obschonka et al. 2012).

Studies on AEI have generally analyzed different antecedents of intention, both individual (Prodan, \& Drnovsek 2010; Huyghe, \& Knockaert, 2015; Goethner et al., 2012; Obschonka et al., 2012, 2015; Feola et al., 2017) and contextual factors (Moog et al., 2015; Foo et al., 2016; Guerrero \& Urbano, 2014; Goel, Goktepe-Hulten, \& Ram, 2015; Erikson, Knockaert, \& Der Foo, 2015).

For instance, Obschonka et al. (2012) found that an important feature that elucidates academicians' intent toward entrepreneurship is social identity, that indicates a status in which an individual identifies his/herself as belonging to a group of peers in the academic environment. Similarly, Huyghe and Knockaert (2015) highlighted the role of universities' culture and climate in affecting AEI and they found that the latter is higher when universities are more committed to an entrepreneurial goal.

Some authors combined different types of dimensions in investigating entrepreneurial intention of academic people. Goethner et al. (2012) analyzing proximal predictors and some economic factors, such as connections with the support of public subjects, patenting experiences and expected financial return (considered some distal predictors of intentions) in influencing AEI, showed that the latter have only an indirect impact on AEI, first working on shaping perceived behavioral control and attitudes.

Feola et al. (2017), proposing a combination of behavioral and exogenous/environmental factors, demonstrated the role of the three Helices of the THM (Etzkowitz, \& Leydesdorff 1995; Etzkowitz et al. 2007) in shaping attitude and in determining AEI. In particular, integrating TPB and THM, authors demonstrated that government support and university support are heavy antecedents of attitude whereas industrial and financial support and government support directly shape AEI.

Among numerous theories adopted to study the formation of a behavior toward entrepreneurship (Guerrero et al. 2008), the TPB (Ajzen, 1991) represents one of the most applied theories (Lortie \& Castrogiovanni, 2015). Further, it has been demonstrated being the most powerful theory in explaining different kinds of entrepreneurial intention (Liñán et al. 2011; Delmar, \& Wiklund 2008). TPB model has also been used in the academic context in order to analyze AEI (Goethner et al., 2012; Obschonka et al., 2012, 2015). The TPB identifies three antecedents of the intention to engage in an entrepreneurial behavior: Entrepreneurial Attitude (EA), Perceived 
Behavioral Control (PBC) and Subjective Norms (SN). EA refers to the personal beliefs about the specific behavior. $\mathrm{PBC}$ refers to the perception of personal capacity to realize a given behavior. SN refers to the perception of social pressure towards the specific behavior.

\subsection{Triple Helix Model and Academic Entrepreneurship}

Carayannis and Campbell (2009) emphasize the idea that innovation ecosystems strongly impact on innovation and entrepreneurial processes. Innovation ecosystems enclose a set of different resources that range from human and social capital to cultural and technological aspects that interacting each other continually co-evolve and co-specialize (Carayannis, 2001). Innovative networks embody infrastructures and technologies that are central in raising creativity, triggering inventions and catalyzing processes of innovation in public and/or private domains (Carayannis \& Alexander 2004).

Thinking about the dynamics of innovations and entrepreneurial activities in a knowledge-based economy, the contribution of the innovative network of industries, universities and government has been extensively investigated in entrepreneurship research (Kim, Kim, \& Yang, 2012). More specifically, the innovation system has been defined and contextualized in the THM proposed by Etzkowitz and Leydesdorff (1995; Etzkowitz et al., 2000 , 2007). THM sustains the idea that the creation of a virtuous innovation system is based on three helices that, interacting each other in a mutual synergy, play a specific role in sustaining entrepreneurship. The three Helices of the model are Industry/Finance, University and Government (Etzkowitz et al., 2007).

First, the business environment in which universities operate, consisting of industry and finance, can contribute giving fundamental assets to the formation and implementation of academic spin-offs (Fini, Grimaldi, Santoni, \& Sobrero, 2011). Several studies have highlighted that venture capital has a great importance in determining the growth of investments in R\&D activities and in the increase of patents, on the new ventures' professionalization and on the availability of some resources and skills (Kortum, \& Lerner, 1998; Hellman, \& Puri, 2002; Baum, \& Silverman, 2004). In the same way, beyond offering financial support, the presence of a relevant industrial sector at local level and of related industries can stimulate the foundation of start-ups and help simplifying the transfer of information and knowledge spillovers (Audretsch, 2005; Acs, Audretsch, \& Lehmann, 2013).

Second, universities and academic environments contribute to stimulate their researchers' inclinations toward entrepreneurship and holds the birth of academic spin-offs through the promotion of different supporting actions (Fini et al. 2011; Mustar, \& Wright 2010).

Third, the government, at different levels (supranational, national and local), acts by adopting laws and regulations that encourage and support the creation and development of innovative start-ups. In this sense, entrepreneurial activities find support thanks to the setting of a series of rules and regulatory activities issued by the government. Even more, among the activities that define the importance of the role of government there are the furniture of financial supports and facilities, i.e. incubators and scientific parks (Fini et al. 2011), considered important elements in the promotion of entrepreneurial patterns and innovation-driven start-ups.

\section{Theoretical Framework and Hypotheses Development}

The aim of this study is to focus on the interplay between the classical determinants of behavioral intention as conceptualized in the TPB (namely EA, PBC and SN) and the perceived support of some elements of the external innovation ecosystem, identified adopting the THM framework (namely Industry \& Finance, University and Government), on AEI.

In most of the evidences in entrepreneurship research focusing on cognitive processes, EA and PBC have been considered basic antecedents of entrepreneurial intentions (Autio, Keeley, Klofsten, Parker, \& Hay, 2001; Krueger et al., 2000). In the specific domain of academia, similar conclusion made researches focused both on students and academics (Yurtkoru, Kuscu, \& Doganay, 2014; Goethner et al., 2012). Among TPB's constructs, $\mathrm{SN}$ is the most controversial. Indeed, studies and evidences in academic entrepreneurship have demonstrated divergent and contrasting results, showing a positive impact (Obschonka et al., 2012; Iakowleva, Kolvereid, \& Stephan 2011) or weak and no significant effect (Goethener et al., 2012; Liñán \& Chen 2009; Krueger et al., 2000, Autio et al. 2001) on entrepreneurial intentions. Despite these reported contrasting evidences, we move from the seminal prescription from Ajzen (1991) and we felt appropriate to retest the positive impact of SN on AEI.

Therefore, we formulate the resulting hypotheses:

H1: EA is positively related to AEI.

H2: $\mathrm{PBC}$ is positively related to AEI. 


\section{H3: $\mathrm{SN}$ is positively related to AEI.}

To better assess the role of the context as a factor that can implement and reinforce individuals' cognitive patterns and their transition to entrepreneurship as a possible and feasible career choice, some authors underline the importance of individuals' perceptions of innovation ecosystem that might influence their entrepreneurial decisions (see for example Tang, 2006; Levie, \& Autio 2011). Ecosystem affects innovation processes positively, embody a set of different resources that range from human, social, intellectual and financial capital that, interacting each other, continually co-evolve and co-specialize (Carayannis, 2001). According with the THM (Etzkovitz et al., 2007), these innovation networks and knowledge clusters are strongly embedded within heterogeneous socio-economic, political, institutional, and technological domains which include within them, among others, Industry/Fincance, University and Government. Therefore, this study proposes that the perceived contextual conditions will interact with cognitive behavioral, normative and control beliefs that in turn form the confidence to give birth to a new venture. More precisely, we contend that when individuals perceive the positive support of these environmental elements the feedback is a significant stronger and positive transition from cognition to concrete intention.

Extant research suggests that high financial and industrial support relation with academics has been demonstrated to be a strong factor in stimulating entrepreneurial activity (Beck, Demirguc-Kunt, \& Maksimovic, 2005), through the availability of capital and the involvement in technology transfer processes. The existence of a dynamic and innovative competitive environment and the access to capitals are generally considered as elements capable to foster entrepreneurial ventures (Covin \& Slevin, 1989; Beck et al., 2005). For example, Rahm (1994) found that when academics develop relations with industrial environment they are more willing to be involved in technology transfer processes. Davidsson and Honig (2003) stress that being part of a business network, as well as having previous start-up experience, have a significant positive effect on business creation. Referring to perceived financial support, a number of studies have highlighted that one of the main obstacle to students' entrepreneurship and entrepreneurial behavior is represented by the narrow accessibility to capital (Mustar \& Wright 2010), leading to the expectation that perceiving a high support from financial environment could serve as a strong motivation toward entrepreneurship. However, some of the new businesses fail independently from the financial support they receive or despite the support they receive. Probably, it is logical to argue that industrial and financial support do not necessarily have a direct relationship on intention but interact with the cognitive dimension (as represented by the TPB components) of the process, modifying the direct relation between cognitive structures and intention itself. Hence, we can put the subsequent hypotheses:

H4 Perceived industrial and financial support increases the positive relationship between TPB antecedents and AEI and more clearly the following

H4a Perceived industrial and financial support improves the positive relationship between EA and AEI.

H4b Perceived industrial and financial support improves the positive relationship between PBC and AEI.

H4c Perceived industrial and financial support improves the positive relationship between SN and AEI.

In the field of entrepreneurship, literature has shown that education (and entrepreneurial education) gathered by universities, mixing knowledge and inspiration for entrepreneurial tasks, strongly predicts students' entrepreneurial intention (Bae, Qian, Miao, Fiet, 2014; Fayolle \& Gailly, 2015; Turker, \& Selcuk 2009). Similar results join several studies (Saeed, Yousafzai, Yani-De-Soriano, \& Muffatto, 2015), that have found that intentions are strongly and significantly predicted by academic support. Other studies have underlined the heterogeneous nature of the educational context support that in some cases has different beneficiaries, mobilizes different kind of resources and provides support in different forms (Fini et al. 2011). Feola et al. (2017) found that perceived University support affects attitude toward entrepreneurial behavior significantly, but it doesn't have any direct effect on intentions of academics to start a new business. Similarly, other studies in the entrepreneurship field report not significant or negative results on the effect of entrepreneurship education on cognitive structure and intention (Lanero et al., 2015; Mentoor \& Friedrich, 2007; Chang \& Rieple, 2013). A considerable agreement exists on considering entrepreneurship education a powerful factor in spreading and increasing nascent/potential entrepreneurs' perception and attitudes toward entrepreneurship (Potter, 2008). According to Lüthje and Franke (2003), public policy and academic environment play a determinant role in the implementation of activities aimed at intensifying educational programs and research centered on entrepreneurship. Moreover, Türker and Selçuk (2009) enlightened that university education shapes necessary knowledge about entrepreneurship and, working on people interest and awareness about entrepreneurship as a possible career choice, increases the supply of potential and nascent entrepreneurs. Only recently, in an effort to identify an agreement on the variables that impact on individuals' decision to start up a venture, strong interest 
has turned to cognitive approaches (Baron, 2004; Krueger, 2003), but there is still a lack of consensus on this issue. Some studies highlight that university support, in term of availability of technology transfer office or patent office or incubator (Mustar \& Wright 2010; Mian, 1996; Rothaermel \& Thursby 2005), has positive role in business creation. Consequently, it seems coherent to retain that university support, interacting with the knowledge dimension of the decision-making, modifies the relation between the traditional cognitive variables and intention itself, increasing overall their predictive power.

In this sense, it seems reasonable to put the subsequent hypotheses:

H5 Perceived university support accentuates the positive relationship between TPB antecedents and AEI and more clearly the following

H5a Perceived university support accentuates the positive relationship between EA and AEI.

H5b Perceived university support accentuates the positive relationship between PBC and AEI.

H5c Perceived university support accentuates the positive relationship between SN and AEI.

Literature on institutional support of entrepreneurship has gained some controversial results. On the one hand, government constitutes the main source from which emanates the amount of rules and normative conditions for boosting innovative ventures, providing financial incentives as well as physical infrastructures (i.e. science parks, incubators, Fini et al. 2011) that have been documented representing significant features to promote and encourage entrepreneurship and innovative ventures. On the other hand, some government regulations can discourage individuals from starting a business (Lim, Morse, Mitchell, \& Seawright, 2010). Examples include obtaining permits and licenses (Van Stel, Storey, \& Thurik, 2007; Klapper, Laeven, \& Raghuram, 2006), higher taxation (Keuschnigg \& Nielsen, 2004), obstacles to adapting to labor market regulations (Grossman \& Shapiro, 1982), as well as bankruptcy legislation. All these institutional-driven elements could negatively affect the level of entrepreneurship (Armour \& Cumming, 2006; Lee et al., 2011). Government policies shape the institutional environment, that is the place where entrepreneurial decisions are taken, and consequently they are important for entrepreneurship development (Minniti, 2008). In fact, North (1990) highlights that the institutional environment, shaping the rules of the game, has a fundamental role in determining the boundaries of human actions, and ideally reduces uncertainty. Because of that Minniti (2008, p. 781) states “... institutions (and the policies that shape them) are crucial in determining entrepreneurial behavior". More clearly, literature review emphasizes that motives that drive intention to become entrepreneurs do not change time by time (Baumol, 1990). What changes over time are the institutions and the rules that institutions set in building the environment in which business decisions are made. Therefore, it seems coherent to assume that perceiving favorable regulations and government actions rather than having a direct effect on the cognitive process, can impact on the cognitive process that links the traditional perceptive variables with respect to the intention to become entrepreneur. Thus, we can hypothesize the following:

H6 Perceived government support increases the positive relationship between the TPB antecedents and AEI and more clearly the subsequent

H6a Perceived government support boosts the positive relationship between EA and AEI.

H6b Perceived government support boosts the positive relationship between PBC and AEI.

H6c Perceived government support boosts the positive relationship between SN and AEI.

The Figure 1 presents the theoretical model derived from the above-mentioned hypotheses.

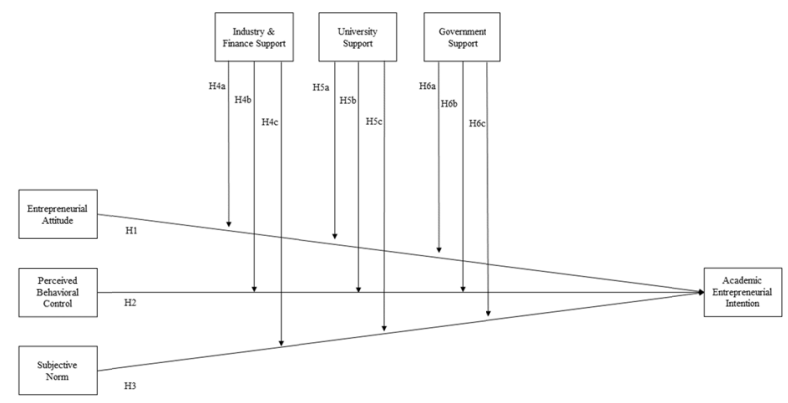

Figure 1. Theoretical Model of the study 


\section{Data and Methods}

\subsection{Sample and Data Collection}

To test the hypotheses of our proposed model an online survey has been administered. Data were gathered between June and December 2017, from approximately 2,000 Ph.D. students at soft sciences and hard sciences departments of several academic poles (University of Rome "La Sapienza", University of Rome "Tor vergata", Politecnico di Bari, Quaid-e-Azam university, Iqra University) located in two different countries (namely, Italy and Pakistan). The questionnaire has been developed in English. Then, a professional translator and a professor in entrepreneurship who is fluent in both languages have translated it into Italian. Prior to launch the survey, a test with two groups of independent Phd students has been taken to guarantee the clarity of the wording. The same procedure was adopted for the Pakistan survey.

\subsection{Variables and Measures}

As suggested by Kline (2005) and Churchill (1979), we adopted multi-items scales to measure our constructs, deriving all the variables used in our research from prior studies. All the measures adopted in this study and their sources are presented in the Appendix.

Academic entrepreneurial intention was measured adopting Liñán, and Chen (2009) and Prodan, and Drnovsek (2010) scales, adapting three items.

To measure TPB variables this study partially adapted the measurement proposed by Ajzen (1991), Yurtkoru et al. (2014), Fini et al. (2012), Kautonen, van Gelderen, \& Fink (2015). In particular, TPB dimensions were operationalized with 14 items in total, of which eight items to measure EA, three items to measure PBC and three items to measure SN.

Similarly, we operationalized THM variables following measurement elaborated and tested by Fini et al. (2009; 2012) and enlarging the scale proposed by Feola et al. (2017), using 10 items: three to measure perceived industrial and financial support, four to measure perceived university support and three to measure perceived government support. In particular, adapting the measure proposed by Fini et al. (2012) and Fini, Grimaldi \& Sobrero (2009), we used three items to measure industrial and financial support to assess how academics view business angels or venture capital to be supportive and the existence of industries to be useful to improve their activity. We operationalized university support with four statements that evaluate to what extent academics consider a business plan competition, an academic technology transfer office (TTo), admission to an academic incubator, an academic patent office helpful in new venture creation resulted from research activity. We measured government support with three items to estimate how is considered relevant for the new business development the fact that government supports financially and with regulations the new innovative start-ups. For all the variables adopted in our study, with the exception of entrepreneurial attitude (surveyed with a semantic bi-polar scale), respondents were invited to rate their level of agreement/disagreement with survey's statement on a 7-point Likert scale or, for the three elements of THM, to what extent each factor (industry/finance, university and government) was considered supportive for new ventures creation. We then perform different exploratory factor analysis (principal component analysis) for each multiple-item series to obtain a standardized score for the latent dimension to which each series respectively refers to.

In addition to the variables of specific interest, we also control for several respondent specific factors that could influence our results. Therefore, we include some individual socio-demographic features (i.e. gender, marital status, age) and academic and professional information (research hours per week, number of years since the researcher started his research activity, Phd year and professional experience).

\subsection{Analytical Method}

Empirical analysis has been developed in two phases, following suggestions from Anderson and Gerbing (1988). First, to estimate the measurement model, a confirmatory factor analysis (CFA) has been run. In the second phase, the proposed hypotheses were verified adopting a hierarchical regression analysis in three steps. In the first model we introduced only the control variables; in the second model we added the main antecedent of intention in the TPB (namely EA, PBC and SN) to test H1, H2 and H3. Finally, in the model 3 the interplay among TPB's cognitive determinants and THM contextual factors was assessed, including in the empirical analysis the interaction effects between each of the three contextual dimensions and the three variables that represent the traditional dimensions of the TPB, to scrutinize hypothesis H4 (i.e., H4a, H4b and H4c), H5 (i.e., H5a, H5b and H5c), and H6 (i.e., H6a, H6b and H6c). A spotlight analysis has been performed to discuss the role of each interaction term. 


\section{Results}

\subsection{Summary Statistics, Correlations, and Reliability of the Measurement Model}

Table 1 shows summary statistics regarding the respondent sample used in our analysis. There were more males (62.4 percent) than females (37.6 percent) in the sample. 75.8 percent of the respondents have been involved in a research program from an extent of at least four years and less than $11 \%$ have been involved for more than six years. Much of the respondents (79.5 percent) were single and less than 26 years old (77.3 percent); in the sample were present heterogeneous occupations, comprising 33.4 percent of professional, 22.6 percent of employee, and 9.2 percent of non-professional. 30.0 percent of the sample have never been employed before. 123 of the respondents are from Italy and the remaining part (287) are from Pakistan.

Table 1. Sample characteristics

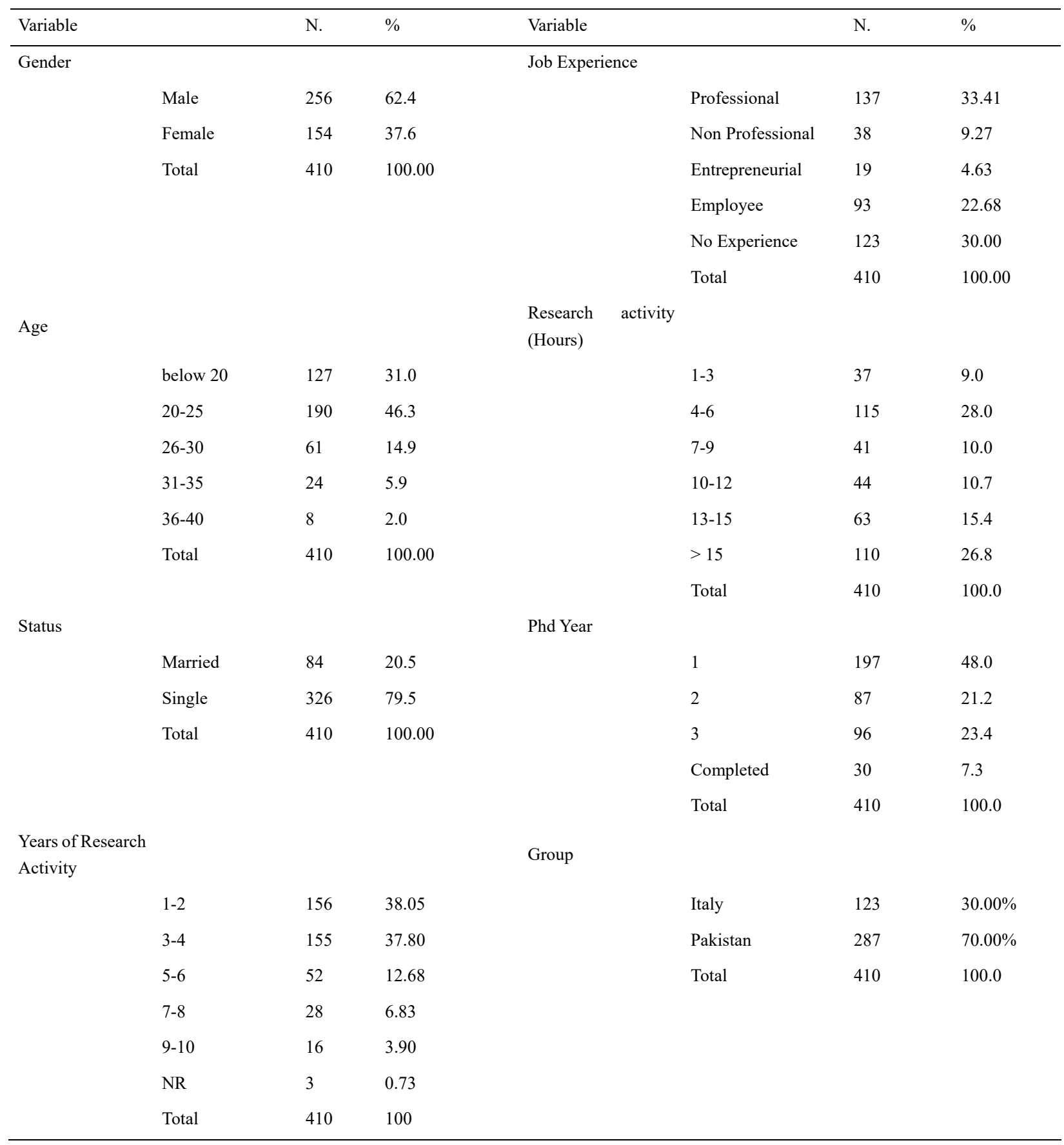


As reported in the Appendix section, for all the multi-items constructs we performed a CFA to assess reliability, convergent and discriminant validity. In Table 2 the Cronbach alphas and the standardized factor loading computed by the CFA are shown, demonstrating an excellent reliability for all the constructs, as can be seen from Table 3 in the Appendix, in which it has been displayed that all alpha and composite reliability (CR) values respect the criteria suggested by Nunnally and Bernstein (1994). The measurement model fit the data sufficiently as demonstrated by the common fit indices $\left(\chi^{2}=822,060, \mathrm{df}=300,\left(\chi^{2} / \mathrm{df}=2.740, \mathrm{CFI}=0.935, \mathrm{SRMR}=0.0514\right.\right.$, $\mathrm{TLI}=0.924$ and RMSEA $=0.065$ with $\mathrm{p}$-close $=.000)$. Each composite reliability $(\mathrm{CR})$ and average variance extracted (AVE) value (Table 3) meets the minimum threshold of 0.7 and 0.5 respectively (Garbarino \& Johnson, 1999; Hair, Black, Babin, \& Anderson, 2010), so convergent validity is well satisfied. Moreover, we found that the AVE of each latent dimension is higher than the highest squared correlation with any other latent dimension; thus, discriminant validity is not an issue in this study (Fornell, \& Larcker, 1981). Moreover, running regression analysis, the variance inflation factor (not reported) for each regression testing the conceptual framework has been computed and no value exceeding 2.63 has been found. This result also provides good confidence that multicollinearity is not a problem.

Table 2. Confirmatory factor analysis results

\begin{tabular}{|c|c|c|c|c|c|}
\hline Latent Dimension & Code & $\begin{array}{c}\text { Standardized } \\
\text { Coefficient }\end{array}$ & T-value & Sig. & Cronbach \\
\hline \multirow{8}{*}{ Attitude } & ATTIT1 & .762 & 16.401 & $* * *$ & \multirow{8}{*}{.943} \\
\hline & ATTIT2 & .785 & 17.005 & $* * *$ & \\
\hline & ATTIT3 & .77 & - & - & \\
\hline & ATTIT4 & .761 & 20.697 & $* * *$ & \\
\hline & ATTIT5 & .868 & 19.299 & $* * *$ & \\
\hline & ATTIT6 & .871 & 19.376 & $* * *$ & \\
\hline & ATTIT7 & .887 & 19.813 & $* * *$ & \\
\hline & ATTIT8 & .808 & 17.633 & $* * *$ & \\
\hline \multirow{3}{*}{$\begin{array}{l}\text { Perceived } \\
\text { Behavioral Control }\end{array}$} & $\mathrm{PBC} 1$ & .772 & 18.588 & $* * *$ & \multirow{3}{*}{.876} \\
\hline & $\mathrm{PBC} 2$ & .88 & - & - & \\
\hline & PBC3 & .873 & 22.118 & $* * *$ & \\
\hline \multirow{3}{*}{ Subjective Norm } & SN1 & .79 & - & - & \multirow{3}{*}{.861} \\
\hline & $\mathrm{SN} 2$ & .963 & 19.453 & $* * *$ & \\
\hline & SN3 & .728 & 15.986 & $* * *$ & \\
\hline Academic & AEI1 & .925 & - & - & \\
\hline Entrepreneurial & AEI2 & .934 & 29.311 & $* * *$ & .886 \\
\hline Intention & AEI3 & .703 & 17.595 & $* * *$ & \\
\hline \multirow{3}{*}{$\begin{array}{l}\text { Industrial and } \\
\text { Financial Support }\end{array}$} & IND/FIN_SUPP1 & .828 & - & - & \multirow{3}{*}{.864} \\
\hline & IND/FIN_SUPP2 & .891 & 19.878 & $* * *$ & \\
\hline & IND/FIN_SUPP3 & .755 & 16.715 & $* * *$ & \\
\hline \multirow{4}{*}{ University Support } & UN_SUPP1 & .801 & - & - & \multirow{4}{*}{.878} \\
\hline & UN_SUPP2 & .887 & 18.914 & $* * *$ & \\
\hline & UN_SUPP3 & .761 & 16.184 & $* * *$ & \\
\hline & UN_SUPP4 & .705 & 14.715 & $* * *$ & \\
\hline \multirow{3}{*}{$\begin{array}{l}\text { Government } \\
\text { Support }\end{array}$} & GOV_SUPP1 & .873 & - & - & \multirow{3}{*}{.796} \\
\hline & GOV_SUPP2 & .578 & 12.096 & $* * *$ & \\
\hline & GOV_SUPP3 & .826 & 18.882 & $* * *$ & \\
\hline
\end{tabular}


Table 3. Correlation matrix for latent constructs - composite reliability and average variance extracted ${ }^{*}$

\begin{tabular}{|c|c|c|c|c|c|c|c|c|c|}
\hline & CR & AVE & 1 & 2 & 3 & 4 & 5 & 6 & 7 \\
\hline 1 - AEIntention & .894 & .741 & .861 & & & & & & \\
\hline 2 - Attitude & .941 & .665 & .523 & .816 & & & & & \\
\hline 3 - PBControl & .880 & .711 & .671 & .467 & .843 & & & & \\
\hline 4 - SNorm & .870 & .694 & .398 & .297 & .535 & .833 & & & \\
\hline 5 - Univ_Supp & .869 & .626 & .391 & .301 & .397 & .314 & .791 & & \\
\hline 6 - Gov_Supp & .809 & .593 & .381 & .263 & .318 & .277 & .673 & .770 & \\
\hline 7 - IndFinSup & .866 & .683 & .232 & .173 & .213 & .263 & .517 & .726 & .827 \\
\hline
\end{tabular}

* In bolded, square roots of the AVE are reported.

\subsection{Assessing Common Method Variance}

In order to ensure that common method variance is not a concern of our findings, we estimated two models and measured fit statistics (Williams, Cote, \& Buckley, 1989; Podsakoff, MacKenzie, Lee, \& Podsakoff, 2003; Tang, Kacmar, \& Busenitz, 2012). In the first model all the items load on their theoretical latent variable. In the second model, a latent common method variance factor was added to the first model, allowing all the items to load on it. Comparing the different fit statistics for the two models reveals that they did not increase after the addiction of uncorrelated factor method. Results are provided in the Table 4 suggesting that common method variance is not a serious issue in this study. Additionally, in the Appendix we present also CFA results.

Table 4. Test for Common Method Variance: fit statistic of the measurement model with or without latent factor

\begin{tabular}{|c|c|c|}
\hline Fit indeces & Model with latent factor & Model without latent factor \\
\hline$\chi^{2} / \mathrm{df}$ & 2.657 & 2.740 \\
\hline CFI & .938 & .935 \\
\hline TLI & .928 & .924 \\
\hline RMSEA & .064 & .065 \\
\hline SRMR & .0515 & .0514 \\
\hline
\end{tabular}

\subsection{Hierarchical Regression Analysis}

In order to test the hypotheses, we conducted a hierarchical regression analysis in three steps. The independent variables were entered after the baseline model with only control variables, followed by the interaction term. Table 5 displays the results of the regression analysis.

Table 5. Regression analysis (dependent variable: Academic Entrepreneurial Intention)

\begin{tabular}{|c|c|c|c|}
\hline Variables & Model 1 & Model 2 & Model 3 \\
\hline \multirow{2}{*}{ Gender } & $-.155^{* *}$ & -.019 & -.013 \\
\hline & $(-3.083)$ & -.472 & -.355 \\
\hline \multirow{2}{*}{ Status } & -.009 & $.087^{+}$ & $.136^{* *}$ \\
\hline & $(-.154)$ & (1.877) & (3.168) \\
\hline \multirow{2}{*}{ Age_by_class } & .076 & .061 & $.116^{*}$ \\
\hline & $(1.124)$ & $(1.169)$ & 2.398 \\
\hline \multirow{2}{*}{ Hour_by_class } & .001 & -.058 & -.023 \\
\hline & $(.015)$ & $(-1.056)$ & $(-.453)$ \\
\hline \multirow{2}{*}{ research_activity_years } & $-.202^{* *}$ & $-.151^{* *}$ & $-.117^{* *}$ \\
\hline & $(-3.336)$ & $(-3.253)$ & $(-2.741)$ \\
\hline \multirow{2}{*}{ PhD Year } & .077 & $.080^{+}$ & .054 \\
\hline & 1.293 & $(\mathbf{1 . 7 5 3 )}$ & $(1.277)$ \\
\hline
\end{tabular}




\begin{tabular}{|c|c|c|c|}
\hline Professional & $\begin{array}{c}.114^{+} \\
(1.815)\end{array}$ & $\begin{array}{c}.085^{+} \\
(1.772)\end{array}$ & $\begin{array}{c}.110^{*} \\
(2.415)\end{array}$ \\
\hline \multirow{2}{*}{ Non Professional } & -.005 & .024 & -.050 \\
\hline & $(-.092)$ & $(.562)$ & $(-1.256)$ \\
\hline \multirow{2}{*}{ Entrepreneurial } & -.020 & .007 & .030 \\
\hline & $(-.369)$ & $(.164)$ & $(.775)$ \\
\hline \multirow{2}{*}{ No Experience } & .013 & -.011 & .009 \\
\hline & $(.194)$ & $(-.226)$ & $(.187)$ \\
\hline \multirow{2}{*}{ Group } & $.191^{* *}$ & .029 & $.158^{* *}$ \\
\hline & $(2.663)$ & $(.510)$ & (2.874) \\
\hline \multirow{2}{*}{ Attitude } & & $.273^{* * *}$ & $.293^{* * *}$ \\
\hline & & $(6.425)$ & 6.919 \\
\hline \multirow{2}{*}{ PBC } & & $.446^{* * *}$ & $.365^{* * *}$ \\
\hline & & 9.103 & (7.757) \\
\hline \multirow{2}{*}{ SN } & & $.087^{*}$ & .053 \\
\hline & & 1.988 & $(1.280)$ \\
\hline \multirow{2}{*}{ Ind_Fin_Supp } & & & $.143^{* *}$ \\
\hline & & & (2.836) \\
\hline \multirow{2}{*}{ Uni_Supp } & & & -.014 \\
\hline & & & $(-.301)$ \\
\hline \multirow{2}{*}{ Gov_Supp } & & & .072 \\
\hline & & & $(1.522)$ \\
\hline \multirow{2}{*}{ Attitude x_Ind_Fin_Supp } & & & .065 \\
\hline & & & $(1.223)$ \\
\hline \multirow{2}{*}{ PBC x Ind_Fin_Supp } & & & .084 \\
\hline & & & $(1.333)$ \\
\hline \multirow{2}{*}{ SN x Ind_Fin_Supp } & & & -.070 \\
\hline & & & $(-1.058)$ \\
\hline \multirow{2}{*}{ Attitude x Uni_Supp } & & & $.165^{* *}$ \\
\hline & & & $(2.845)$ \\
\hline \multirow{2}{*}{ PBC x Uni_Supp } & & & $-.226^{* * *}$ \\
\hline & & & $(-3.654)$ \\
\hline \multirow{2}{*}{ SN x Uni_Supp } & & & $.186^{* *}$ \\
\hline & & & $(2.767)$ \\
\hline \multirow{2}{*}{ Attitude x Gov_Supp } & & & $-.124^{*}$ \\
\hline & & & $(-2.130)$ \\
\hline \multirow{2}{*}{ PBC x_Gov_Supp } & & & $-.136 * *$ \\
\hline & & & $(-2.512)$ \\
\hline \multirow{2}{*}{ SN x Gov_Supp } & & & $-.123^{+}$ \\
\hline & & & $(-1.896)$ \\
\hline \multirow{2}{*}{ Constant } & -.256 & $-.834^{+}$ & $-1.281^{* *}$ \\
\hline & $(-.435)$ & $(-1.875)$ & $(-2.982)$ \\
\hline N. Observ & 410 & 410 & 410 \\
\hline $\mathrm{R}^{2}$ & .286 & .515 & .582 \\
\hline Adjusted $\mathrm{R}^{2}$ & .082 & .494 & .554 \\
\hline Change in $\mathrm{R}^{2}$ & - & $.044^{* * *}$ & $.067^{* * *}$ \\
\hline F-Value & $3.226^{* * *}$ & $24.516^{* * *}$ & $20.513^{* * *}$ \\
\hline
\end{tabular}

Bolded values are significant at: ${ }^{+} \mathrm{p}<.1{ }^{*} \mathrm{p}<.05{ }^{* *} \mathrm{p}<.01^{* * *} \mathrm{p}<.001$.

Regarding control variables, Model 1 demonstrates that gender $(p<.01)$, research activity years $(p<.01)$, respondent country $(p<.01)$, and professional experience $(p<.1)$ have a statistically significant relationship with AEI. These results suggest that (1) men are oriented to start a business starting from their research results much more than women; (2) the longer an individual has been involved in a research activity, the weaker entrepreneurial intention she/he has; (3) the Pakistani sample demonstrates a higher entrepreneurial intention 
than Italian group; professionalism instead of working as an employee makes the difference in starting a business.

As Model 2 in Table 2 shows, standardized Betas for $\mathrm{EA}(\beta=.273 ; \mathrm{t}=6.425 ; \mathrm{p}<.001), \mathrm{PBC}(\beta=.446 ; \mathrm{t}=9.103 ; \mathrm{p}$ $<.001)$, and $\mathrm{SN}(\beta=.087 ; \mathrm{t}=1.988 ; \mathrm{p}<.05)$ are positive and strongly significant explaining a little bit less than half of the variance in the dependent variable, which confirm our H1, H2 and H3 and assess the validity of the TPB in explaining individuals' intentions (Ajzen, 1991). Model 3 demonstrate that industrial and financial support is not a good moderator of the relationships between the TPB variables and Intention, therefore H4 (a,b and $\mathrm{c}$ ) is overall not supported. On the contrary, university support appears to significantly moderate the relationships between EA and intention $(\beta=.165 ; \mathrm{t}=2.845 ; \mathrm{p}<.01)$, the relationship between PBC and intention $(\beta=-.226 ; t=-3.654 ; p<.001)$, and also the relationship between $\mathrm{SN}$ and intention $(\beta=-.186 ; \mathrm{t}=-2.767 ; \mathrm{p}<.01)$. In more clear words, university support appears to positively emphasize the relationship between EA and intention as such: the higher university support is, the better EA explains the formation of entrepreneurial intention of young researcher. On the contrary, university support appears to negatively accentuate the relationship between $\mathrm{PBC}$ and intention as such: the higher university support is, the less PBC explains the formation of entrepreneurial intention of young researcher. In the same sense, university support appears to negatively accentuate the relationship between SN and intention as such: the higher university support is, the less SN explains the emergence of entrepreneurial intention of young researcher. Therefore, we found partially support for H5. Similarly, government support appears to significantly moderate the relationships between EA and intention $(\beta=-.124 ; \mathrm{t}=-2.130 ; \mathrm{p}<.05)$, the relationship between $\mathrm{PBC}$ and intention $(\beta=-.136 ; \mathrm{t}=-2.512 ; \mathrm{p}$ $<.05)$, and also the relationship between $\mathrm{SN}$ and intention $(\beta=-.123 ; \mathrm{t}=-1.896 ; \mathrm{p}<.1)$. In particular, the higher government support is, the less EA, PBC and SN explain the formation of entrepreneurial intention of young researchers. As such, we found empirical support for $\mathrm{H} 5 \mathrm{a}$, and $\mathrm{H} 5 \mathrm{c}$, being also statistically significant the interaction hypothesized in H5b, H6a, H6b, and H6c. To better asses the significant moderating effects, we conducted a spotlight analysis of each interaction (Figures 2-7). Figure 2 and 4 demonstrate that, when university support is high, the effect of EA (and of $\mathrm{SN}$ ) on intention are respectively higher than when university support is low. As can be seen from figure 3, under low university support, the impact of PBC on AEI is higher than under high university support. Finally figures 5, 6 and 7 respectively show that when government support is high, the effects of EA, PBC and SN on intention are lower than when government support is low.

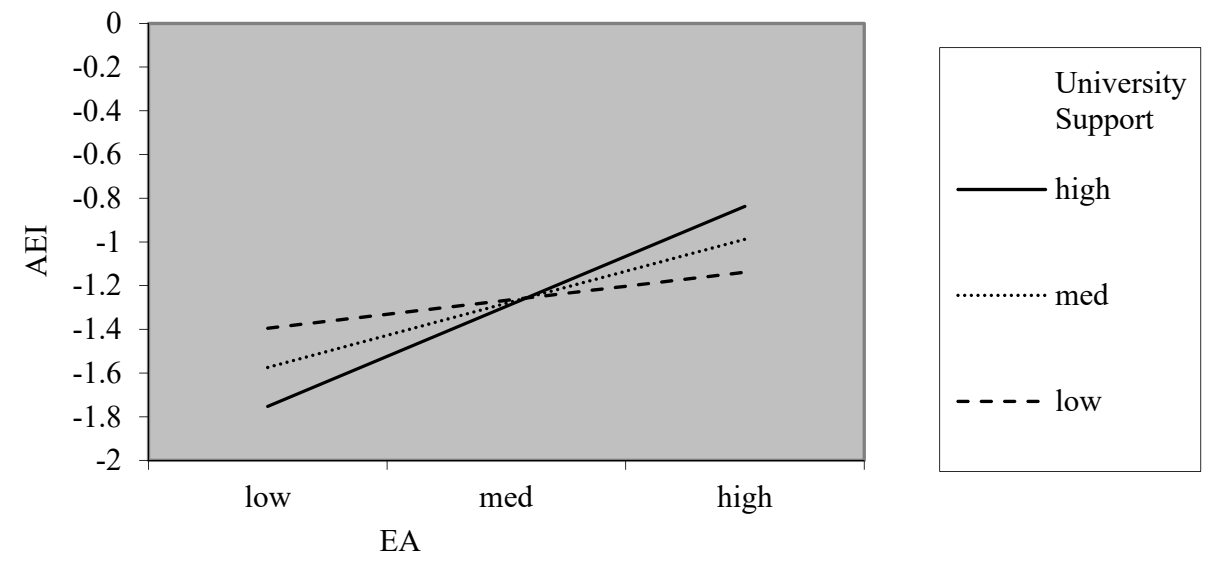

Figure 2.Plot of the interaction between university support and entrepreneurial attitude 


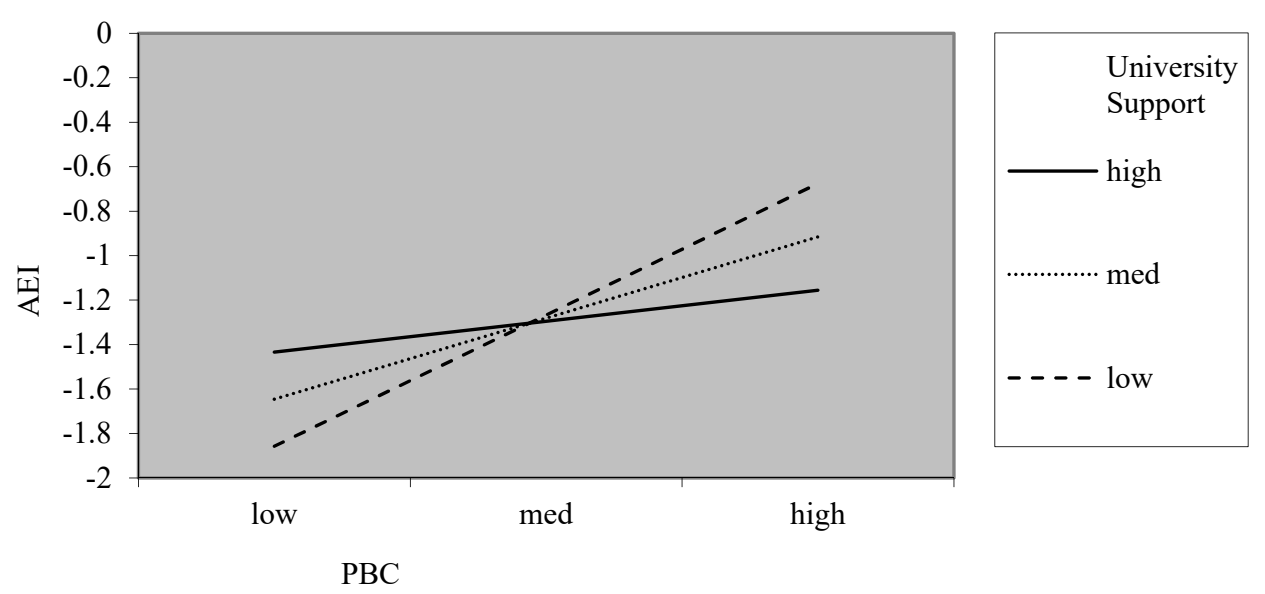

Figure 3. Plot of the interaction between university support and perceived behavioural control

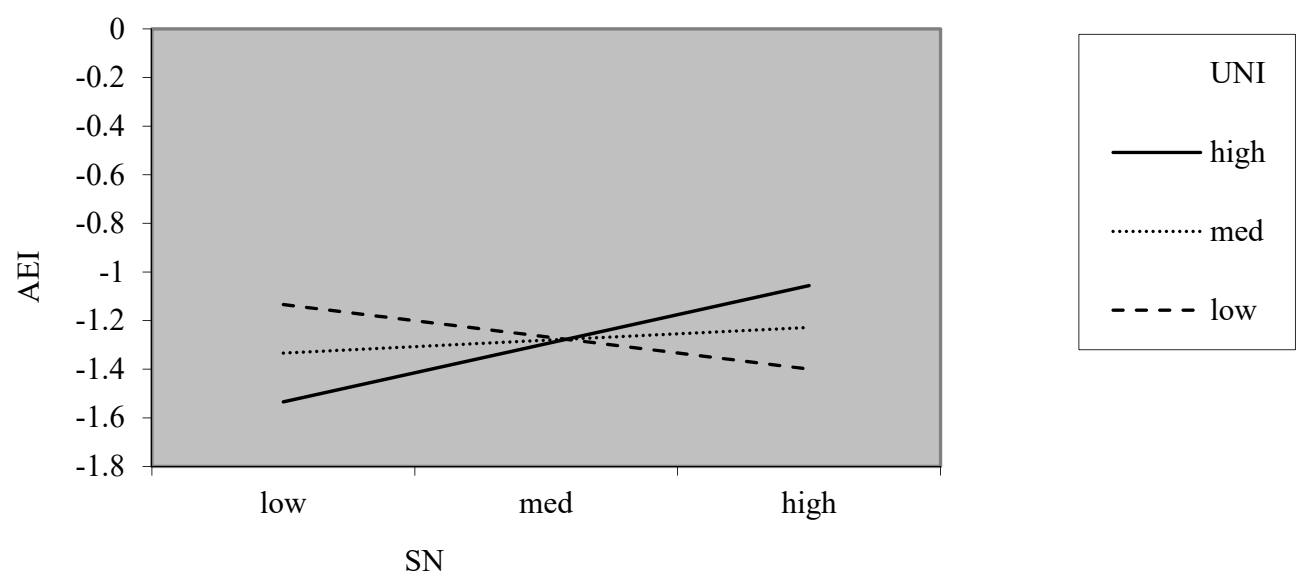

Figure 4. Plot of the interaction between university support and subjective norm

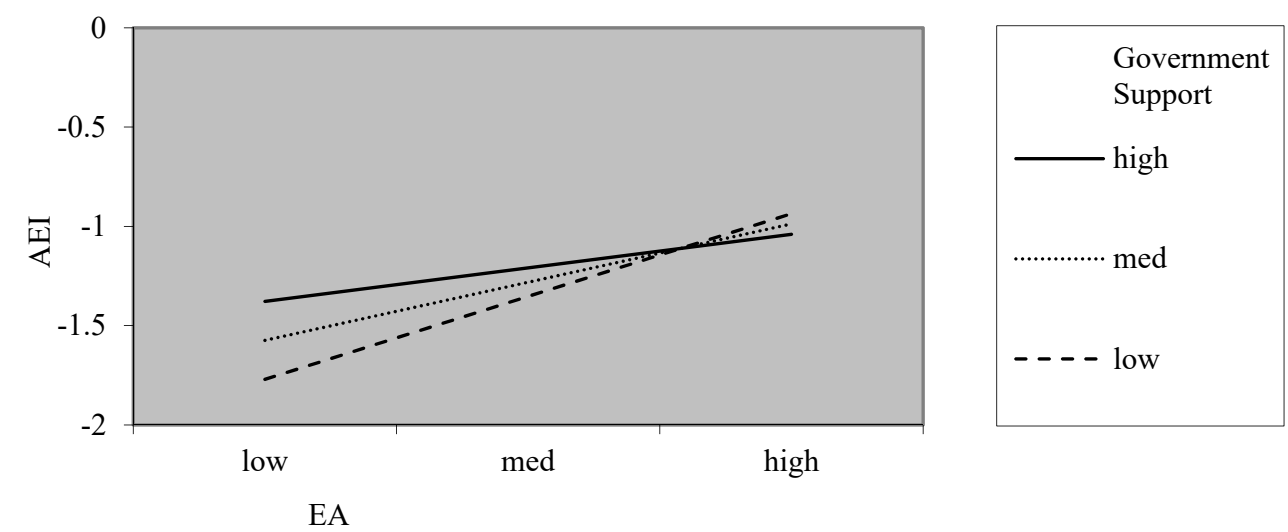

Figure 5. Plot of the interaction between government support and entrepreneurial attitude 


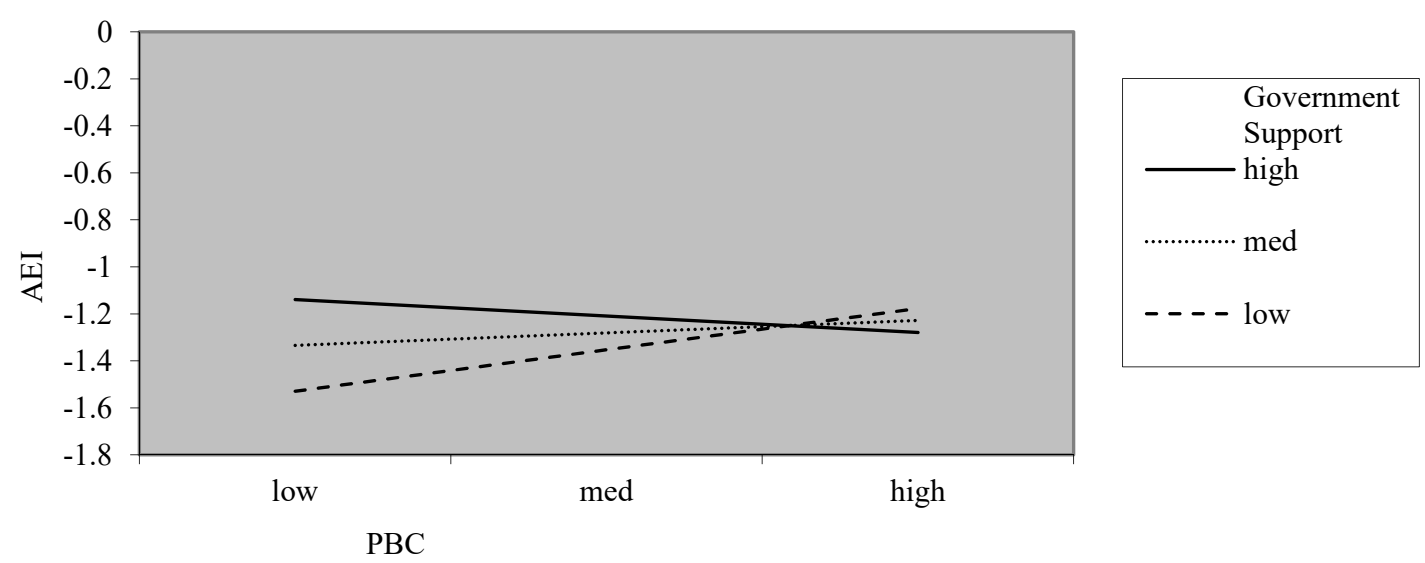

Figure 6. Plot of the interaction between government support and perceived behavioural control

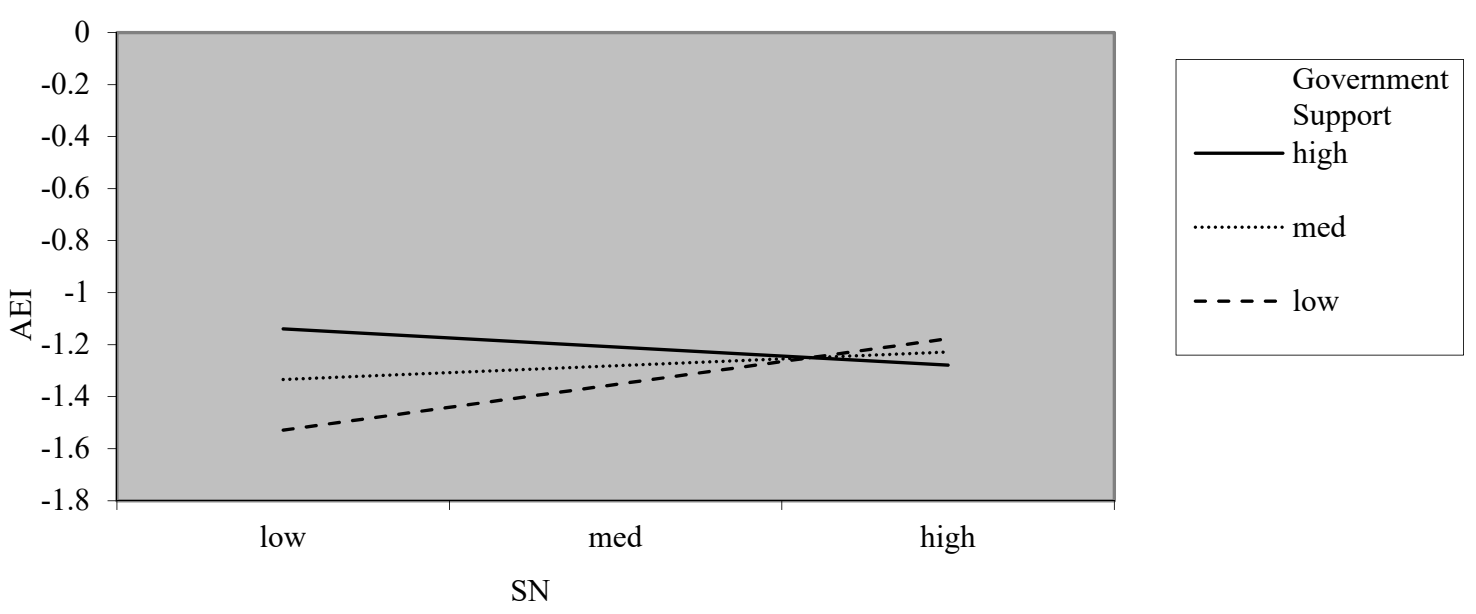

Figure 7. Plot of the interaction between government support and subjective norm

\section{Discussion}

Extant research on AEI fails to address the interplay between endogenous (psychological) and exogenous (contextual) level factors, from a cognitive perspective, whereas many researchers (Cooke \& Sheran, 2004; Carsrud \& Brännback, 2011; Moriano et al., 2012; Shook et al., 2003; Liñán et al., 2011; Schlaegel \& Koenig, 2013) acknowledge the importance of studying the moderating effects of perceived contextual factors and environment in order to understand the well-established direct effects of psychological determinants.

Therefore, the present study moves from two theories, namely the TPB (Ajzen, 1991) and the THM (Etzkowitz et al., 2007), in order to investigate the moderating effects of some relevant dimensions of external environment (Industry and Finance, University, Government) on the relationships between the cognitive dimension (EA, PBC and SN) and AEI.

The results of this study confirm the predictive power that the TPB has in predicting academic entrepreneurial intentions. As such we find support for $\mathrm{H} 1, \mathrm{H} 2$ and $\mathrm{H} 3$ demonstrating that EA, PBC and SN have positive influence on AEI, in line with others studies (Yurtkoru et al., 2014; Obschonka et al., 2012; Autio et al., 2001).

Overall, our results identify interesting interaction effects between TPB and the environmental context (as represented by industry/finance, university and government).

Moderating hypotheses of industrial and financial support on AEI (namely H4a, H4b and H4c) was not supported from our results. Following Lee (1996), we could consider that academics are mainly fearful that 
industrial and financial involvement might limit academic freedom, that can be defined as the capability to perform curiosity-driven research without getting involved in commercial gain. However, academics appear to be able to set bounds between what they retain as legitimate forms of industrial involvement, and what they judge as a commercial driven one (Lee, 1996). Moreover, it is also plausible to contend that the perception of external support comes into play at later stages, when nascent entrepreneurs are concretely taking steps in the development of entrepreneurial initiatives and, in order to achieve success, they may consider external support more carefully (Fini et al., 2012).

Perceived university support and perceived government support appear to shape both behavioral and volitional beliefs among young researcher (hypothesis $\mathrm{H} 5 \mathrm{a}$ and $\mathrm{H} 5 \mathrm{c}$ are, in fact, clearly confirmed; although not completely supporting hypothesis H5b, H6a, H6b and H6c, data show an important moderating effect on traditional antecedents of intention). More specifically the moderating effect of university support is positive on EA and SN, while it is negative on PBC. In other words, when the support of university is high, the positive effect of EA and SN on AEI is amplified. Therefore, university support is a factor that strengthens the positive effect of EA and SN on AEI. Vice versa, the moderating effect of university support on PBC is negative. Consequently, when the support of university is high the positive effect of PBC on AEI is lower. So, university support is a factor that weakens the positive effect of PBC on AEI. An explanation of this results could be the following. Referring to university education, it seems that more specific knowledge on entrepreneurship makes people more aware of entrepreneurial difficulties and risks and it slightly reduces their AEI. Other studies in the entrepreneurship field report not significant or negative results on the impact of entrepreneurship education on cognitive structure and intention (Lanero et al., 2007; Mentoor \& Friedrich, 2007; Chang \& Rieple, 2013). In addition, one of the most classical precepts of ancient Greek philosophes attributed from Plato to Socrates is the idea that the more I know, the more I know I do not know (Plato 1967). In the entrepreneurship context we can say "The more I am aware of the difficulties, the less I am willing to risk". If this assumption is accepted, we can suggest as managerial implication to join university support with incentives to reduce uncertainty and perceived risk. In this sense government support takes a central role.

Finally, perceived government support moderates the relationship between EA, PBC and SN control negatively. In other words, when the support of government is high, the positive effect each TPB variables on AEI overall decreases. Therefore, government support is a factor that weakens the positive effect of TPB constructs on AEI. An explanation of this result, related to our sample, should be the following: Italy and Pakistan are countries both characterized by bureaucracy and government inefficiency. This fact could affect negatively the expectation of effective government support. Similar result is found by Kazumi and Kawai (2017, p. 359) which studied female entrepreneurs across Japan and verified "... that formal institutional support has a positive effect but shows no statistical significance in predicting the level of women's self-efficacy". Authors believe that "...lack of self-confidence in their own abilities may be reinforced by a lack of credibility in government support policies that offer tangible assistance to foster entrepreneurial skills and know-how" (Kazumi \& Kawai, 2017 p. 359). On the same line, Lim et al. (2010) suggest that high regulatory complexity and heavy bureaucracy may decrease entrepreneurial intention, consequently hindering the generation of a positive attitude. The contextual conditions of Italy and Pakistan, their high level of bureaucracy (Note 1) probably make people, and young people inter alia, little confident about government support or possibly also negative minded. So, the perception (good or bad) of government support and bureaucracy could be factors that interact differently on the relationship between government support and AEI. In this sense, the relation should be verified comparing countries with different level of bureaucracy, so future researches on these aspects could lead to interesting results.

\section{Implications}

The research aimed to study the factors that affect entrepreneurial intention among academicians (Prodan \& Drnovsek, 2010). In order to test our contentions, we developed a framework in which the classical intention determinants derived from the TPB (Ajzen, 1991) interact with some elements of the environmental innovation ecosystem as identified in the THM (Etzkovitz et al., 2007), namely finance/industry, university and government supports. We maintain that when individuals perceive high support from all these factors, the predictive power of attitude, perceived behavioral control and social norms in shaping academic entrepreneurial intention generally increases. The present study brings to some implication, both theoretical and practical.

Conceptualizing a model that regards at the same time psychological/endogenous and environmental/exogenous factors, we contribute to the academic entrepreneurship research field and more specifically to the literature on AEI (Ozgul \& Kunday, 2015; Prodan \& Drnovsek, 2010; Fini et al., 2009). This stream of research has, over time, paid great attention to individual and psychological variables only separately, neglecting to deeply assess their interaction in determining AEI from a cognitive perspective. Overall, our findings support all the direct 
influences of the TPB on AEI, whereas we found contrasting results about the moderating influences. Moderating influence of industrial and financial support on AEI was not supported from our results, the moderating effect of university support was positive on EA and SN, while it was negative on PBC, and perceived government support moderated the relationship between EA, PBC and SN control negatively.

About practical implication, having highlighted the relevance of the innovation ecosystem variable (namely perceived industrial/financial, university and government support) and of university support, inter alia, in moderating the direct relationships between TPB dimensions and AEI, this study has several implications in terms of strategies and actions aimed at stimulating the entrepreneurial intentions of academics. In terms of implications and policies, in line with other studies, to stimulate the academics' intention to become entrepreneurs, universities, through the determination of incentive resources for entrepreneurial actions, can implement the development of structures such as technology transfer offices (TTo). This suggestion is also in accordance with existing studies (see for example Mustar, \& Wright, 2010) centered on TTo's role in enhancing entrepreneurial consciousness and a positive mood of academics toward the opportunity of turning their research activity into a new business idea. Moreover, another important group of policies that can contribute to shape academicians' entrepreneurial intentions refers to implement the role of university incubators in supporting spin-offs in the first phases of development (Rothaermel, \& Thursby, 2005; Mian, 1996). Finally, for policymakers that aim to better understand how to increase the level of entrepreneurial engagement, a suggestion derived from this study is to boost effective dialogue with young researchers to deeply understand their needs and desires in terms of knowledge about funding methods, support systems and entrepreneurial education.

\section{Conclusions, Limitations and Future Research Suggestions}

The present work isn't without limitations that could contribute to future research developments. First, we led this research in two different countries, an Asian and a European country, where probably we found some specificity compared to cultural features that may affect the results. Moreover, the two countries have two different economic developments: Pakistan is a developing country while Italy is a developed one. To improve the robustness of our model, it would be interesting to compare our results with larger samples in different world economies. Moreover, comparison between different countries and their regulatory, economical, or simply contextual conditions could be developed in further research trajectories on this topic. Second, since we employed a questionnaire for the cross-sectional nature of our research design, we didn't obtain direct behavioral measures, being this study limited only to register an entrepreneurial intention of each participant to the survey. To overcome this limitation, longitudinal study could also reveal if academic entrepreneurial intention effectively leads to academics' specific behavior of being entrepreneurs. Third, the operationalization of industry and finance, university and government support, has been conducted in only few studies without paying a strong attention to assess the psychometric properties of the scales. Although this study did not overcome this limitation, this is one of the first studies to propose the operationalization of these dimensions. In this sense, our findings should be further validated with more empirical evidences carried out in different contexts, developing scales that fully respect psychometric properties adopting a behavioral approach in the measurement of industry/finance, university and government support.

\section{References}

Acs, Z. J., Audretsch, D. B., \& Lehmann, E. E. (2013). The knowledge spillover theory of entrepreneurship. Small Business Economics, 41, 757-774. https://doi.org/10.1007/s11187-013-9505-9

Ajzen, I. (1991). The theory of planned behavior. Organizational behavior and human decision processes, 50(2), 179-211.

Anderson, J., \& Gerbing, D. (1988). Structural modeling in practice: a review and recommended two-step approach. Psychological Bulletin, 103(3), 411-423.

Armour, J., \& Cumming, D. (2006). The Legislative Road to Silicon Valley. Oxford Economic Papers, 58 (4), 596-635

Audretsch, D. B. (2005). The Knowledge Spillover Theory of Entrepreneurship and Economic Growth. Vinig, G.T. and Van Der Voort, R. C. W. (Eds.), The Emergence of Entrepreneurial Economics (Research on Technological Innovation, Management and Policy, Vol. 9, pp. 37-54). Emerald Group Publishing Limited, Bingley, https://doi.org/10.1016/S0737-1071(05)09003-7

Autio, E., R. H., Keeley, M., Klofsten, G. C., \& Parker, M., H. (2001). Entrepreneurial Intent among Students in Scandinavia and in the USA. Enterprise and Innovation Management Studies, 2(2), 145-160.

Bae, T. J., Qian, S., Miao, C., \& Fiet, J. O. (2014). The relationship between entrepreneurship education and 
entrepreneurial intentions: a meta-analytic review. Entrepreneurship Theory \& Practice, 38, 217-254.

Baron, R. A. (2004). The cognitive perspective: a valuable tool for answering entrepreneurship's basic "why" questions. Journal of Business Venturing, 19(2), 221-239.

Baum, J. A., \& Silverman, B. S. (2004). Picking winners or building them? Alliance, intellectual, and human capital as selection criteria in venture financing and performance of biotechnology startups. Journal of business venturing, 19(3), 411-436.

Baumol, W. J. (1990). Entrepreneurship: Productive, unproductive, and destructive. The Journal of Political Economy, 98(5), 893-921.

Beck, T., Demirgüç-Kunt, A. S. L. I., \& Maksimovic, V. (2005). Financial and legal constraints to growth: Does firm size matter? The Journal of Finance, 60(1), 137-177.

Bienkowska, D., Klofsten, M., \& Rasmussen, E. (2016). PhD Students in the Entrepreneurial University Perceived Support for Academic Entrepreneurship. European Journal of Education, 51(1), 56-72.

Carayannis, E. G. (2001). The Strategic Management of Technological Learning. CRC Press, Boca Raton, Florida.

Carayannis, E. G., \& Alexander, J. (2004). Strategy, structure and performance issues of pre-competitive R\&D consortia: insights and lessons learned. IEEE Transactions of Engineering Management, 52(2), 135-139.

Carayannis, E. G., \& Campbell, D. F. J. (2009). 'Mode 3' and 'Quadruple Helix': toward a 21st century fractal innovation ecosystem. International Journal of Technology Management, 46(3), 201-234.

Carsrud, A., \& Brännback, M. (2011). Entrepreneurial motivations: What do we still need to know? Journal of Small Business Management, 49(1), 9-26.

Chang, J., \& Rieple, A. (2013). Assessing students' entrepreneurial skills development in live projects. Journal of Small Business and Enterprise Development, 20(1), 225-241.

Churchill, G. A. (1979). A paradigm for developing better measures for marketing constructs. Journal of Marketing Research, 16(1), 64-73.

Clarysse, B., Heirman, A., \& Degroof, J.J. (2000). An Institutional and Resource Based Explanation of Growth Patterns of Research Based Spin-Offs in Europe. Frontiers of Entrepreneurship Research. Babson Center for Entrepreneurial Studies.

Cooke, R., \& Sheeran, P. (2004). Moderation of cognition-intention and cognition-behaviour relations: A meta-analysis of properties of variables from the theory of planned behaviour. British Journal of Social Psychology, 43(2), 159-186.

Covin, J. G., \& Slevin, D. P. (1989). Strategic management of small firms in hostile and benign environments. Strategic Management Journal, 10, 75-87.

Davidsson, P., \& Honig, B. (2003). The role of social and human capital among nascent entrepreneurs. Journal of Business Venturing, 18(3), 301-331.

Delmar, F., \& Wiklund, J. (2008). The effect of small business managers' growth motivation on firm growth: A longitudinal study. Entrepreneurship Theory and Practice, 32(3), 437-457.

Erikson, T., Knockaert, M., \& Der Foo, M. (2015). Enterprising scientists: The shaping role of norms, experience and scientific productivity. Technological Forecasting and Social Change, 99, 211-221.

Etzkowitz, H., \& Leydesdorff, L. (1995). The Triple Helix-University-industry-government relations: A laboratory for knowledge based economic development. EASST Review, 14(1), 14-19.

Etzkowitz, H., Dzisah, J., Ranga, M., \& Zhou, C. (2007). The triple helix model of innovation: University-industry-government interaction. Asia Pacific Tech Monitor, 24(1), 14-23.

Etzkowitz, H., Webster, A., Gebhardt, C., \& Terra, B.R.C. (2000). The future of the university and the university of the future: evolution of ivory tower to entrepreneurial paradigm. Research Policy, 29(2), 313-330.

Fayolle, A., \& Gailly, B. (2015). The impact of entrepreneurship education on entrepreneurial attitudes and intention: Hysteresis and persistence. Journal of Small Business Management, 53(1), 75-93. https://doi.org/10.1111/jsbm.12065

Feola, R., Vesci, M., Botti, A., \& Parente, R. (2017). The Determinants of Entrepreneurial Intention of Young Researchers: Combining the Theory of Planned Behavior with the Triple Helix Model. Journal of Small 
Business Management, 57(4), 1424-1443. https://doi.org/10.1111/jsbm.12361

Fini, R., Grimaldi, R., \& Sobrero, M. (2009). Factors fostering academics to start up new ventures: an assessment of Italian founders' incentives. The Journal of Technology Transfer, 34(4), 380-402.

Fini, R., Grimaldi, R., Marzocchi, G.L., \& Sobrero, M. (2012). The Determinants of Corporate Entrepreneurial Intention within Small and Newly Established Firms. Entrepreneurship: Theory and Practice, 36(2), $387-414$.

Fini, R., Grimaldi, R., Santoni, S., \& Sobrero, M. (2011). Complements or substitutes? The role of universities and local context in supporting the creation of academic spin-offs. Research Policy, 40(8), 1113-1127.

Foo, M. D., Knockaert, M., Chan, E. T., \& Erikson, T. (2016). The individual environment nexus: Impact of promotion focus and the environment on academic scientists' entrepreneurial intentions. IEEE Transactions on Engineering Management, 63(2), 213-222.

Fornell, C., \& Larcker, D. (1981). Evaluating structural equation models with unobservable variables and measurement error. Journal of Marketing Research, 18(1), 39-50.

Garbarino, E., \& Johnson, M.S. (1999). The Differential Roles of Satisfaction, Trust, and Commitment in Customer Relationships. Journal of Marketing, 63, 70-87.

Goel, R. K., Goktepe-Hulten, D., \& Ram, R. (2015). Academics' entrepreneurship propensities and gender differences. Journal of Technology Transfer, 40(1), 161-177.

Goethner, M., Obschonka, M., Silbereisen, R. K., \& Cantner, U. (2012). Scientists' transition to academic entrepreneurship: Economic and psychological determinants. Journal of Economic Psychology, 33(3), 628-641.

Grossman, G. M. \& Shapiro, C. (1982). A Theory of Factor Mobility. Journal of Political Economy, 90(5).

Guerrero, M., \& Urbano, D. (2014). Academics' start-up intentions and knowledge filters: An individual perspective of the knowledge spillover theory of entrepreneurship. Small Business Economics, 43(1), 57-74.

Guerrero, M., Rialp, J., \& Urbano, D. (2008). The impact of desirability and feasibility on entrepreneurial intentions: A structural equation model. International Entrepreneurship and Management Journal, 4, 35-50.

Hair, J. F., Black, W. C., Babin, B. J., \& Anderson, R. E. (2010). Multivariate Data Analysis. Seventh Edition. Prentice Hall, Upper Saddle River, New Jersey.

Hellmann, T., \& Puri, M. (2002). Venture capital and the professionalization of start-up firms: Empirical evidence. The journal of finance, 57(1), 169-197.

Huyghe, A., \& Knockaert, M. (2015). The influence of organizational culture and climate on entrepreneurial intentions among research scientists. The Journal of Technology Transfer, 40(1), 138-160.

Iakovleva, T., Kolvereid, L., \& Stephan, U. (2011). Entrepreneurial Intentions in Developing and Developed Countries. Education \& Training, 53(5), 353-370.

Kautonen, T., Van Gelderen, M., \& Fink, M. (2015). Robustness of the theory of planned behavior in predicting entrepreneurial intentions and actions. Entrepreneurship: Theory and Practice, 39(3), 655-674.

Kazumi T., \& Kawai, N. (2017). Institutional support and women's entrepreneurial self-efficacy. Asia Pacific Journal of Innovation and Entrepreneurship, 11(3), 345-365.

Keuschnigg, C. \& Nielsen, S.B. (2004). Start-Ups, Venture Capitalists, and the Capital Gains Tax. Journal of Public Economics, 88, 1011-1042.

Kibler, E. (2013). Formation of entrepreneurial intentions in a regional context. Entrepreneurship \& Regional Development, 25(3-4), 293-323. https://doi.org/10.1080/08985626.2012.721008

Kim, Y., Kim, W., \& Yang, T. (2012). The effect of the triple helix system and habitat on regional entrepreneurship: Empirical evidence from the US. Research Policy, 41(1), 154-166.

Klapper, L. F., Laeven, L., \& Raghuram, R. (2006). Entry Regulation as a Barrier to Entrepreneurship. Journal of Financial Economics, 82(3), 591-629.

Kline, R. (2005). Principles and practice of structural equation modeling. NY: Guilford Press.

Kolvereid, L. (2016). Preference for self-employment prediction of new business start-up intentions and efforts. The International Journal of Entrepreneurship and Innovation, 17(2), 100-109. 
Kortum, S., \& Lerner, J. (1998). Does venture capital spur innovation? National bureau of economic research, $28,1-22$

Krueger, N. F. (2003). The cognitive psychology of entrepreneurship. In Z. J. Acs \& D. B. Audretsch (Eds.), Handbook of entrepreneurship research: An interdisciplinary survey and introduction (pp. 105-140). London: Kluwer.

Krueger, N. F., Reilly, M. D., \& Carsrud, A. L. (2000). Competing models of entrepreneurial intentions. Journal of Business Venturing, 15, 411-432.

Lanero, A., Vázquez, J. L., \& Muñoz-Adánez, A. (2015). A social cognitive model of entrepreneurial intentions in university students. Anales de Psicologia/Annals of Psychology, 31(1), 243-259.

Lee, S. H., Yamakawa, Y., Peng, M. W., \& Barney, J. B. (2011). How do bankruptcy laws affect entrepreneurship development around the world? Journal of Business Venturing, 26, 505-520.

Lee, Y. S. (1996). Technology transfer' and the research university: A search for the boundaries of university-industry collaboration. Research Policy, 25(6), 843-863.

Levie, J., \& Autio, E. (2011). Regulatory burden, rule of Law, and entry of strategic entrepreneurs: An International Panel Study. Journal of Management Studies, 48(6).

Lim, D., Morse, E., Mitchell, R., \& Seawright, K. (2010). Institutional environment and entrepreneurial cognitions: a comparative business system perspective. Entrepreneurship Theory and Practice, 34 (3), 491-516.

Liñán, F., \& Chen, Y. W. (2009). Development and Cross-Cultural application of a specific instrument to measure entrepreneurial intentions. Entrepreneurship theory and practice, 33(3), 593-617.

Liñán, F., Urbano, D., \& Guerrero, M. (2011). Regional variations in entrepreneurial cognitions: Start-up intentions of university students in Spain. Entrepreneurship and Regional Development, 23(3-4), 187-215. https://doi.org/10.1080/08985620903233929

Lortie, J., \& Castrogiovanni, G. (2015). The Theory of Planned Behavior in Entrepreneurship Research: What We Know and Future Directions. International Entrepreneurship and Management Journal, 11(4), 935-957.

Lüthje, C., \& Franke, N. (2003). The 'making' of an entrepreneur: testing a model of entrepreneurial intent among engineering students at MIT. $R \& d$ Management, 33(2), 135-147.

Mentoor, E., Friedrich, C., (2007). Is entrepreneurial education at South African universities successful? An empirical example. Industry and Higher Education, 21, 231-232.

Mian, S. A. (1996). Assessing value-added contributions of university technology business incubators to tenant firms. Research policy, 25(3), 325-335.

Minniti, M. (2008). The Role of Government Policy on Entrepreneurial Activity: Productive, Unproductive, or Destructive? Entrepreneurship Theory and Practice, 32(5), 779-790.

Moog, P., Werner, A., Houweling, S., \& Backes-Gellner, U. (2015). The impact of skills, working time allocation and peer effects on the entrepreneurial intentions of scientists. The Journal of Technology Transfer, 40(3), 493-511.

Moriano, J.A., Gorgievski, M., Laguna, M., Stephan, U., \& Zarafshani, K. (2012). A cross-cultural approach to understanding entrepreneurial intention. Journal of Career Development, 39(2), 162-185.

Mosey, S., Noke, H., \& Binks, M. (2012). The influence of human and social capital upon the entrepreneurial intentions and destinations of academics. Technology Analysis \& Strategic Management, 24(9), 893-910.

Mustar, P., \& Wright, M. (2010). Convergence or path dependency in policies to foster the creation of university spin-off firms? A comparison of France and the United Kingdom. The Journal of Technology Transfer, $35(1), 42-65$.

North, D. C. (1990). Institutions, institutional change and economic performance, Cambridge: Cambridge University Press.

Nunnally, J., \& Bernstein, I. (1994). Psychometric theory (3rd ed.). NY: McGraw-Hill.

Obschonka, M., Goethner, M., Silbereisen, R. K., \& Cantner, U. (2012). Social identity and the transition to entrepreneurship: The role of group identification with workplace peers. Journal of Vocational Behavior, 80(1), 137-147. 
Obschonka, M., Silbereisen, R. K., Cantner, U., \& Goethner, M. (2015). Entrepreneurial self-identity: Predictors and effects within the theory of planned behavior framework. Journal of Business and Psychology, 30(4), 773-794.

Ozgul, U., \& Kunday, O. (2015). Conceptual Development of Academic Entrepreneurial Intentions Scale. Procedia-Social and Behavioral Sciences, 195, 881-887.

Peterman, N. E., \& Kennedy, J. (2003). Enterprise education: Influencing students' perceptions of entrepreneurship. Entrepreneurship Theory and Practice, 28(2), 129-144.

Plato (1967). Opere, Vol. I, Laterza, Bari.

Podsakoff, P. M., MacKenzie, S.B., Lee, J.Y., \& Podsakoff, N.P. (2003). Common method biases in behavioral research: A critical review of the literature and recommended remedies. Journal of Applied Psychology, 88(5), 879-903.

Potter, J. (2008), Entrepreneurship and higher education. Paris: OECD_Local Economic and Employment Development (LEED).

Prodan, I., \& Drnovsek, M. (2010). Conceptualizing academic-entrepreneurial intentions: An empirical test. Technovation, 30(5), 332-347.

Rahm, D. (1994). Academic Perceptions of University-Firm Technology Transfer. Policy Studies Journal, 22(2), 267-278.

Rothaermel, F. T., \& Thursby, M. (2005). University-incubator firm knowledge flows: Assessing their impact on incubator firm performance. Research Policy, 34(3), 305-320.

Saeed, S., Yousafzai, S. Y., Yani-De-Soriano, M., \& Muffatto, M. (2015). The role of perceived university support in the formation of students' entrepreneurial intention. Journal of Small Business Management, $53(4), 1127-1145$.

Schlaegel, C., \& Koenig, M. (2014). Determinants of entrepreneurial intent: A meta-analytic test and integration of competing models. Entrepreneurship Theory \& Practice, 38, 291-332.

Shook, C. L., Priem, R. L., \& McGee, J. E. (2003). Venture creation and the enterprising individual: A review and synthesis. Journal of Management, 29(3), 379-399.

Siegel, D. S., \& Wright, M. (2015). Academic Entrepreneurship: Time for a Rethink? British Journal of Management, 26(4), 582-595. https://doi.org/10.1111/1467-8551.12116

Tang, J. (2006). Competition and innovation behavior. Research Policy, 35(1), 68-82.

Tang, J., Kacmar, K. M., \& Busenitz, L. (2012). Entrepreneurial alertness in the pursuit of new opportunities. Journal of Business Venturing, 27(1), 77-94.

Türker, D., \& Selçuk, S. S. (2009). Which factors affect entrepreneurial intention of university students? Journal of European Industrial Training, 33(2), 142-159.

Van Stel, A., Storey, D., \& Thurik, R. (2007). The effect of business regulations on nascent and young business entrepreneurship. Small Business Economics, 28(2-3), 171-186.

Williams, L. J., Cote, J. A., \& Buckley, M. R. (1989). Lack of method variance in self-reported affect and perceptions at work: Reality or artifact? Journal of Applied Psychology, 74, 462-468.

Wilson, F., Kickul, J., \& Marlino, D. (2007). Gender, entrepreneurial self-efficacy, and entrepreneurial career intentions: Implications for entrepreneurship education. Entrepreneurship Theory \& Practice, 31(3), 387-406.

Yurtkoru, E. S., Kuşcu, Z.K., \& Doğanay, A. (2014). Exploring the antecedents of entrepreneurial intention on Turkish university students. Procedia-Social and Behavioral Sciences, 150, 841-850.

\section{Note}

Note 1. In the 2018 index of Economic Freedom (https://www.heritage.org/index/ranking), Italy is 79th and Pakistan 131th. 


\section{Copyrights}

Copyright for this article is retained by the author(s), with first publication rights granted to the journal.

This is an open-access article distributed under the terms and conditions of the Creative Commons Attribution license (http://creativecommons.org/licenses/by/4.0/). 